Estima, D.C.; Martins, F.M.C.P.F.; Rabinovici, A. O papel das Organizações Não-Governamentais ambientalistas no desenvolvimento do turismo sustentável em destinos insulares: estudo de caso Brasil - Portugal. Anais do VIII Congresso Nacional de Ecoturismo e do IV Encontro Interdisciplinar de Ecoturismo em Unidades de Conservação. Revista Brasileira de Ecoturismo, São Paulo, v.4, n.4, 2011, p. 526.

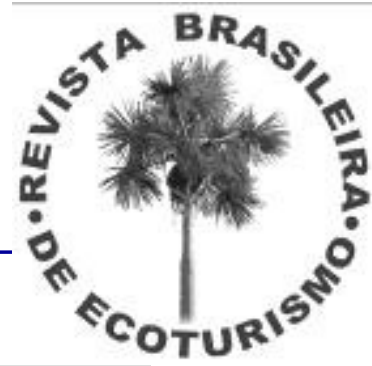

\title{
O PAPEL DAS ORGANIZAÇÕES NÃO-GOVERNAMENTAIS AMBIENTALISTAS NO DESENVOLVIMENTO DO TURISMO SUSTENTÁVEL EM DESTINOS INSULARES: ESTUDO DE CASO BRASIL - PORTUGAL
}

\section{Deborah da Cunha Estima*, Filomena Maria Cardoso Pedrosa Ferreira Martins*, Andréa Rabinovici**}

\author{
*Universidade de Aveiro, ${ }^{* *}$ Universidade Federal de São Paulo
}

E-mails: deborahestima@hotmail.com, filomena@ua.pt, arabinovici@unifesp.br

Cada vez mais o turismo vem-se configurando como fenômeno global fomentando impactos positivos e negativos a nível social, ambiental e econômico. Devido ao seu grande impacto nas sociedades contemporâneas, estudos e pesquisas vêm sendo desenvolvidos no intuito de conhecer e gerir melhor essa atividade de forma sustentável, destacando-se assim a necessidade do envolvimento dos setores público, privado e sociedade civil. Como parte integrante da sociedade civil, as Organizações Não Governamentais ambientalistas (ONGs) têm como principal objetivo a conservação do ambiente. Muitas destas organizações executam ações ligadas à atividade turística. Isso acontece porque o turismo desenvolve-se fundamentalmente em ambientes naturais, onde estas atuam diretamente podendo contribuir de forma significativa para a sustentabilidade da atividade. Esta contribuição é realizada através de várias formas: formulação de diretrizes e estratégias, monitoramento, implementação de programas e projetos de desenvolvimento sustentável alicerçados no turismo, entre outros. Assim, é neste cenário que o interesse desta investigação de doutoramento emerge, com o intuito de identificar a atuação das ONGs relacionadas com a sustentabilidade ambiental associada à atividade turística em contextos territoriais insulares. Para isso, será realizada uma análise comparativa entre ONGs atuantes em Açores (Portugal) e Fernando de Noronha (Brasil). Tendo em vista a forma de atuação diferente, principalmente tratando-se de países distintos, e que afeta diretamente nas competências e nas contribuições à sustentabilidade do turismo, esta análise buscará compreender as práticas atuais e identificar as potencialidades e limitações vivenciadas por estas organizações. A população investigada será composta pelos atores sociais membros ou que são afetados pelos trabalhos das ONGs que desenvolvam alguma ação ligada ao turismo nestes dois ambientes insulares. A metodologia utilizada será a aplicação de entrevistas semi-estruturadas aos responsáveis destas ONGs, culminando numa coleta de dados que possibilitará um novo olhar sobre a atuação destas organizações que são influenciadas diretamente pelo contexto social, político e ambiental no qual atuam. Dessa forma, permitirá, para além de compreender a real contribuição destas organizações para o planeamento e o desenvolvimento do turismo, delinear novas estratégias de cooperação que conduzem para a sustentabilidade do turismo nestes destinos turísticos insulares.

Palavras-chave: Turismo; Organização Não Governamental; Destinos Insulares. 